\title{
KATARA: MODEL HIDROLOGI BERBASIS AGEN (AGENT-BASED MODELLING) UNTUK ANALISIS BANJIR DI DAS CILIWUNG
}

\author{
Aryo Adhi Condro ${ }^{I^{*}}$, Ilham Bayu Widagdo ${ }^{1}$ \\ ${ }^{I}$ Departemen Geofisika dan Meteorologi, FMIPA, Kampus IPB Darmaga Bogor 16680 \\ *Email: aacondro@gmail.com
}

\begin{abstract}
ABSTRAK
Agent-Based Modelling (ABM) merupakan sebuah metode yang dapat menjelaskan sistem secara kompleks dengan sebuah agen yang berperan sebagai individu atau objek yang memiliki orientasi dan aksi tertentu dalam mempengaruhi lingkungan model. KATARA merupakan model hidrologi yang dikembangkan berbasis metode ABM tersebut. Tujuan dari penelitian ini adalah membangun model KATARA dan mengaplikasikanya dalam analisis banjir di DAS Ciliwung. Model KATARA ini dibangun dengan resolusi spasial sebesar $100 x$ $100 \mathrm{~m}$ dan dijalankan dalam skala temporal harian. Data yang digunakan dalam penelitian ini terdiri atas data spasial dalam format ASCII (data tutupan lahan dan data model elevasi) dan data tabular dalam format CSV (i.e.parameter tutupan lahan, parameter cuaca, dan parameter sifat tanah). Interaksi permukaan dengan atmosferdiadopsi berdasarkan konsep dari GenRiver yang mampu menjelaskan proses dinamika hidrologi dengan baik(process based). Air hujan yang menjadi limpasan akan berperan sebagai agen dan mengalir sesuai topografi (patch) yang dilewatinya sehingga sebaran spasial air permukaan dapat terdeteksi secara eksplisit (spatially-explicit). Hasil simulasi model KATARA sesuai dengan tujuan utama pembangunan model, yaitu dapat menjelaskan dinamika interaksi antara atmosfer dan permukaan (process based), dan output model dapat dipahami secara spasial (spatially-explicit). Analisis temporal dan spasial pada hasil simulasi model juga mempunyai similaritas yang tinggi dengan data observasi lapang.
\end{abstract}

Kata kunci: GenRiver, process based, spatialy-explicit

\begin{abstract}
Agent-Based Modeling (ABM) is a methods that can explain a complex system with an agent in which acts as an individual or object that have the orientations and specific actions for influence the environment. KATARA is an agent-based hydrological model. The purpose of this study is to develop the KATARA hydrological model and applied in flood analysis in Ciliwung watershed. KATARA Model have built in $100 \times 100 \mathrm{~m}$ spatial resolution in daily temporal scale. The data used in this study consist of spatial data in ASCII format (i.e. land cover data and elevation model data) and tabular data in CSV format (i.e. land cover parameters, weather parameters and parameters of soil properties). Interactions between surface - atmosphere in this model adopting GenRiver model that can explain the dynamics of hydrological processes very-well (process-based). The net rainfall will act as agent and flow according to the topography (i.e. patch) in it's path - so that the spatial distribution of surface water can be detected spatially-explicit. KATARA model simulation results in accordance with the main objective of development model, that could explain the dynamics of the interaction between the atmosphere and the surface (process-based) and output model can be understood in spatiallyexplicit. Analysis of temporal and spatial simulation models also have a high similarity with observations data.
\end{abstract}

Keywords: GenRiver, process based, spatialy-explicit 


\section{PENDAHULUAN}

\subsection{Latar Belakang}

Banjir merupakan salah satu bencana alam dengan intensitas kejadian yang tinggi di Indonesia. Menurut Badan Nasional Penanggulangan Bencana (BNPB) (2017), hingga februari 2017 bencana banjir menempati urutan pertama sebagai bencana alam yang sering terjadi dengan total 245 kejadian. Banjir di bagian hulu sebuah DAS bercirikan aliran yang deras dengan daya gerus yang besar, namun berdurasi pendek. Sedangkan di bagian hilir arusnya tidak deras, namun berdurasi panjang (Holmes dkk., 2001). Penyebab banjir umumnya merupakan kombinasi dari beberapa faktor, namun kombinasi yang sering menjadi penyebab banjir adalah curah hujan yang tinggi dan kecilnya kapasitas tampung akibat perubahan tata guna lahan. Pengelolaan Daerah Aliran Sungai (DAS) yang buruk merupakan masalah utama dalam alih fungsi lahan, sehingga berdampak nyata terhadap ekosistem yang semakin memburuk dan fungsi DAS y ang tidak berjalan degan semestinya.

DAS Ciliwung merupakan DAS yang sering mendapat banyak perhatian karena dibagian hulunya adalah Jakarta. Hendro dan Fakhrudin (2000) mengemukakan bahwa selama kurun waktu 1990-1996, luas pemukiman di sub DAS Ciliwung telah meningkat secara substansial sebesar $67.88 \%$. Perubahan penggunaan lahan bersifat dinamis terhadap besarnya debit aliran sebagai respon terhadap curah hujan (Asdak 2010). Karakteristik hidrologi DAS ciliwung tidak hanya ditentukan oleh sifat curah hujan, namun juga topografi dan penggunaan lahan. Perubahan penggunaan lahan tersebut berpengaruh sacara nyata terhadap intensitas banjir yang terjadi di DAS Ciliwung (Pawitan 2002).

Estimasi debit banjir 2-tahunan menurut Nedeco-PBJR (1973) adalah $100 \mathrm{~m} 3 / \mathrm{s}$ dan debit banjir 25-tahunan sebesar $200 \mathrm{~m} 3 / \mathrm{s}$, dan nampaknya nilai estimasi ini telah berubah sejalan dengan perubahan penggunaan lahan yang telah terjadi dalam tiga dasawarsa terakhir ini (Pawitan 2002). Analisis bencana banjir dewasa ini banyak memanfaatkan model hidrologi yang mempunyai pendekatan berbeda-beda. Model yang memiliki pendekatan fisik (physically based) yang kompleks sangat akurat dalam mendiskripsikan karakteristik kejadian banjir di tempat tersebut, namun membutuhkan input data yang besar seperti model SHE (Abbot dkk., 1986 dalam Bartholmes dkk., 2005). Model lain yang sering diguankan seperti HBV, Xianjiang Model (lump model) dan ARNO, HEC (semi distributed model) lebih menekankan pada basin response, dan tidak memperhatikan variabilitas output secara spasial (Bartholmes dkk., 2005). Model dengan pendekatan proses (process based) diperlukan untuk menjelaskan proses-proses hidrologi yang terjadi selama banjir berlangsung.

Selain itu, output spasial yang dapat dianalisis secara eksplisit juga diperlukan untuk menunjang pemahaman dan analisis deskriptif lebih lanjut. KATARA merupakan model yang dibangun berbasis Agent-Based Modelling (ABM). ABM dapat mengubah konsep komputasi konvensional yang relatif rumit menjadi lebih sederhana dan mudah dipahami melalui restrukturasi komputasi. ABM merupakan bentuk dari pemodelan komputasional yang menjadikan suatu agen sebagai objek yang berinteraksi di dalam suatu fenomena.

Dalam penelitian ini, air hujan bertindak sebagai sebuah agen yang mengalir sesuai topografi wilayah tersebut, sehingga sebaran spasial air dapat terdeteksi secara eksplisit. Model GenRiver diadopsi dalam membangun model KATARA guna menjelaskan interaksi antara lapisan permukaan dengan atmosfer, meliputi proses presipitasi, intersepsi, evapotranspirasi, serta infiltrasi. Model KATARA ini diharapkan dapat melengkapi beberapa kekurangan dari model hidrologi lainya, sehingga analisis terhadap bencana banjir dapat lebih mendalam dalam berbagai aspek.

\subsection{Tujuan}

Tujuan dari penelitian ini adalah membangun dan mengembangkan model hidrologi berbasis Agent Based Modelling (ABM) untuk analisis banjir dengan mengambil studi kasus di DAS Ciliwung.

\section{METODE PENELITIAN}

\subsection{Daerah Kajian}

Total luas daerah aliran sungai ciliwung sebesar $347 \mathrm{~km} 2$ dengan panjang sungai utama $117 \mathrm{~km}$. Secara hidrologi DAS Ciliwung dapat dibagi 
menurut zonasi toposekuensnya, yaitu: bagian hulu yang merupakan pegunungan antara $300 \mathrm{~m}$ sampai $3000 \mathrm{~m}$; bagian tengah yang merupakan daerah bergelombang dan berbukit-bukit dengan variasi ketinggian antara $100 \mathrm{~m}$ sampai $300 \mathrm{~m}$; dan bagian hilir, merupakan dataran rendah dengan topografi landai antara $0 \mathrm{~m}$ sampai 100 m (Pawitan 2002).

Letak astronomi dan batas DAS Ciliwung dapat dilihat pada gambar 1. Pada penelitian ini, wilayah kajian untuk validasi data secara spasial dilakukan pada tiap zonasi troposekuensnya secara umum, dan pada bagian hilir (DKI Jakarta) secara khusus. Sedangkan untuk analisis output model secara temporal dilakukan dengan skala harian dan bulanan.

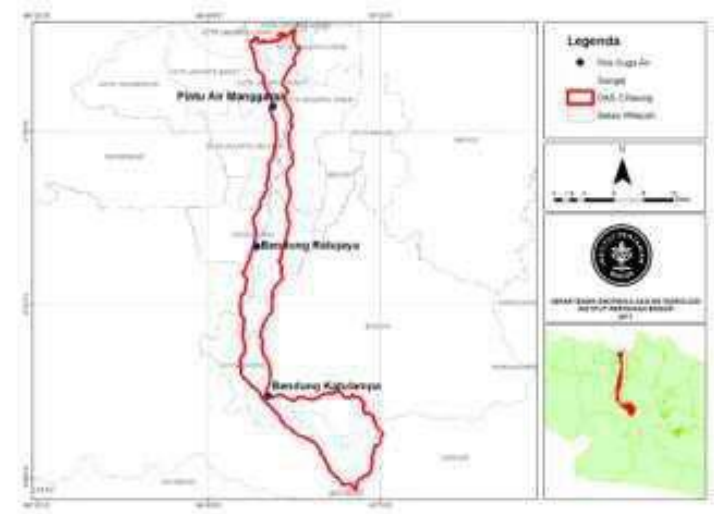

Gambar 1. Peta DAS Ciliwung.

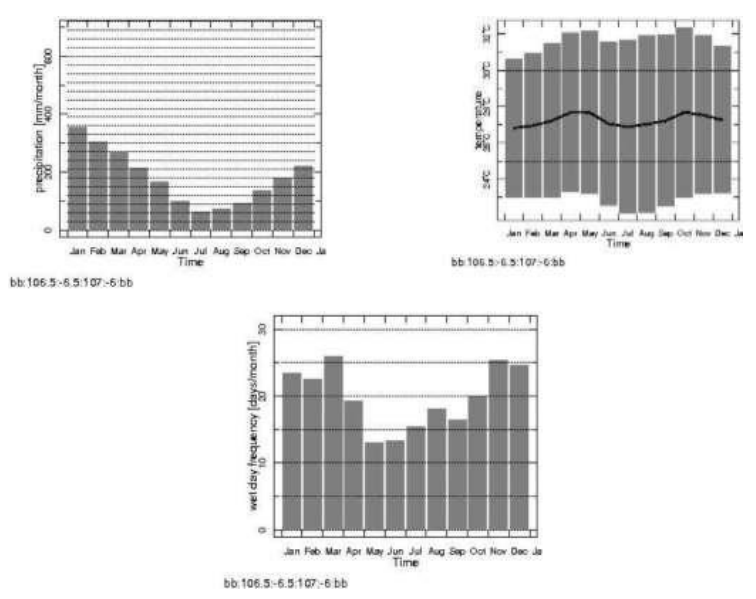

Gambar 2. Karakteristik iklim wilayah DAS Ciliwung. (Sumber: http://iridl.ldeo.columbia.edu/).

Keadaan iklim dan cuaca di wilayah DAS Ciliwung dapat dijelaskan oleh gambar 2 . Curah hujan per bulanya adalah 195-200 mm dan rata-rata hari hujan per bulanya adalah 16 hari. Kelembaban uda ra berkisar antara 80-95 $\%$.

\subsection{Alat dan bahan}

Seperangkat komputer yang dilengkapi dengan perangkat lunak ArcGIS 10.3, Microsoft Excel 2016, serta NetLogo 3D 5.13 digunakan untuk pengolahan data. Perangkat lunak ArcGIS 10.3 digunakan untuk pengolahan data spasial, dan NetLogo 3D 5.3.1 yang dilengkapi dengan ekstensi Geographical Information System (GIS) digunakan untuk membangun model hidrologi di DAS Ciliwung. NetLogo merupakan bahasa pemrograman yang dikembangkan oleh Uri Wilensky yang dapat digunakan dalam pemodelan berbasis agen.

Perangkat lunak NetLogo dapat diunduh melalui tautan (https://ccl.northwestern.edu/netlogo/download. html). Data yang digunakan dalam penelitian ini terdiri dari data spasial (i.e. data elevasi, presipitasi, dan data tutupan lahan) dan data tabular (data mikrometeorologi, parameterisasi lahan, dan data observasi tinggi muka-air).

Model elevasi berasal dari SRTM DEM $30 \mathrm{~m}$ yang telah di-resampling menjadi $100 \mathrm{~m}$, data dapat diunduh pada laman (https://gdex.cr.usgs.gov). Data presipitasi harian berasl dari CHIRPS yang di-resampling $100 \mathrm{~m}$, data diperoleh di laman (http://iridl.ldeo.columbia.edu/SOURCES/.UCS B/.CHIRPS/.v2p0/.daily/.global/.0p05/.prcp/).

Data tutupan lahan diperoleh melalui Badan Informasi Geospasial (BIG) dengan skala 1:250000 yang dapat diunduh di (https://tanahair.indonesia.go.id/home). Data mikrometeorologi diperoleh dari POWER NASA yang bisa diunduh pada laman (https://eosweb.larc.nasa.gov/sse/RETScreen/).

Data tinggi muka air dan $\mathrm{CH}$ observasi di DAS Ciliwung hulu (Bendung Katulampa, Gadog) diperoleh dari Pusat Penelitian dan Pengembangan Sumberdaya Air (Pusair).

Data parameterisasi lahan dan tanah diperoleh melalui studi literatur. Parameter curah hujan, mikrometeorologi, dan data tinggi muka air mengguakan data tahun 2014. Model elevasi digunakan untuk membangun algoritma aliran air, peta tutupan lahan digunakan untuk memperoleh karakteristik hidrologi di DAS Ciliwung, dan data tinggi muka air digunakan untuk validasi luaran model. 


\subsection{Metode}

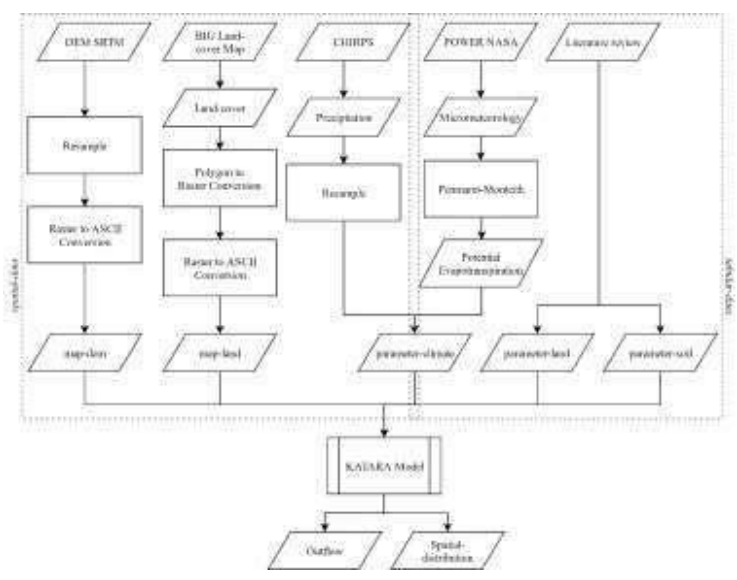

Gambar 3. Diagram alir metode penelitian

Tahap awal dalam penelitian ini adalah persiapan data masukan. Data raster elevasi yang telah di-resample dan data tutupan lahan dikonversi menjadi data ASCII menggunakan conversion tools pada ArcMap 10.3 sehingga menghasilkan data map-dem dan map-land.

Model Penmann-Monteith digunakan untuk mengestimasi evapotranspirasi potensial lahan berdasarkan data mikrometeorologi. Studi literatur dilakukan untuk memperoleh parameter-parameter hidrologi lahan dan sifat tanah wilayah kajian.

KATARA merupakan model hidrologi spasial yang terdiri atas interaksi permukaan-atmosfer dan algoritma aliran permukaan. Model ini dibangun berbasis agen yang dijalankan pada platform NetLogo 3D 5.3.1. Konsep ABS yang merupakan dasar pengembangan model KATARA dijelaskan oleh algoritma ketetanggaan pada gambar 4. Model KATARA memiliki resolusi spasial sebesar $100 \mathrm{~m}$ (1 ha per piksel) dan resolusi temporal harian. Luaran model yang telah dijalankan berupa data spasial (ASCII) dan data tabular (CSV) tinggi muka-air rata-rata per piksel lahan (harian dan bulanan).

Aliran permukaan atau overland flow terjadi ketika lapisan bawah-permukaan jenuh. Pergerakan aliran dipengaruhi oleh topografi wilayah kajian. Aliran dari piksel tertentu akan bergerak menuju piksel tetangganya yang memiliki elevasi dan tinggi genangan paling rendah. Interaksi air antara lapisan permukaan dengan atmosfer terdiri dari proses presipitasi, intersepsi, evapotranspirasi, serta infiltrasi. Beberapa persamaan yang digunakan dalam menjelaskan proses hidrologi permukaan diadopsi dari model GenRiver (van Noordwijk dkk. 2003).

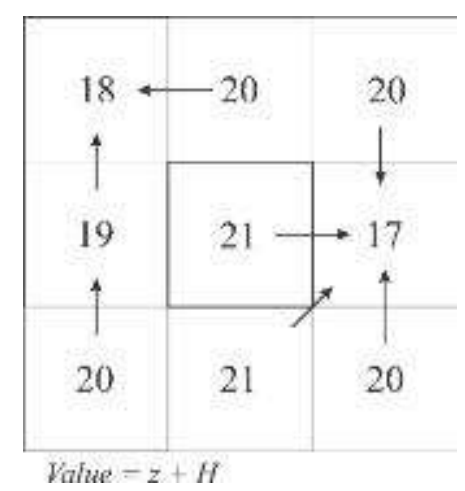

Gambar 4. Algoritma ketetanggaan piksel (100x100 m) pada aliran permukaan.

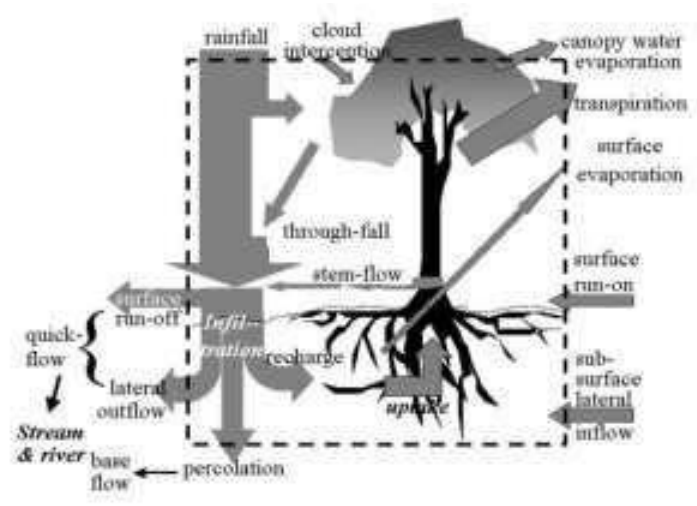

Gambar 5. Konsep neraca air yang dijalankan GenRiver Model pada tiap patch(Sumber: (van Noordwijk dkk. 2003).

Intersepsi aktual merupakan kehilangan air yang terjadi akibat penahanan air hujan pada tajuk tanaman sehingga air akan kembali ke atmosfer. Parameter tersebut dipengaruhi oleh karakteristik kanopi, intersepsi potensial, serta presipitasi yang terjadi pada waktu tertentu. Berikut ini merupakan persamaan yang digunakan untuk menduga intersepsi aktual.

$$
I_{a}=I_{p}\left(1-\exp \left(-\frac{P g}{I_{p}}\right)\right)
$$

Dimana $I a$ adalah intersepsi aktual (mm), Ip merupakan intersepsi potensial $(\mathrm{mm})$, dan $P g$ merupakan presipitasi total atau presipitasi di atas tajuk tanaman $(\mathrm{mm})$. Selanjutnya, proses infiltrasi (Inf) dipengaruhi oleh intensitas hujan neto yang mencapai lapisan permukaan, 
kapasitasi infiltrasi maksimum, serta kapasitas jenuh tutupan lahan.

$$
\operatorname{Inf}=\min (\min (S C-H),(\operatorname{Infmax} \times t 24),(P g-I a))
$$

Dimana Inf merupakan infiltrasi $(\mathrm{mm}), S C$ merupakan kapasitas jenuh tanah $(\mathrm{mm}), H$ merupakan kadar air aktual $(\mathrm{mm})$ dan $I n f_{\max }$ merupakan kapasitas maksimum infiltrasi $(\mathrm{mm}), t_{24}$ adalah durasi rata-rata hujan dalam sehari (24 jam). Kapasitas maksimum infiltrasi dipengaruhi oleh rasio antara $B D$ dengan bulk density referensi pada tutupan lahan hutan $\left(B D_{\text {ref }}\right)$. Evapotranspirasi potensial atau ETP $(\mathrm{mm})$ diduga menggunakan model PenmanMonteith (Allen dkk., 1998). Evapotranspirasi aktual (ETA) dihitung berdasarkan nilai ETP yang telah dikoreksi oleh faktor koreksi ETP $\left(k_{\mathrm{o}}\right)$. Parameter $\beta$ merupakan kadar air relatif pada tutupan lahan tertentu.

Berikut ini merupakan persamaan evapotranspirasi aktual yang digunakan dalam model KATARA.

$$
\begin{aligned}
E T A & =\beta[(E T P \times k o)-(c \times)] \\
\beta & =\frac{H}{R \times \theta} \quad
\end{aligned}
$$

Persamaan (4) menjelaskan kadar air relatif yang dipengaruhi oleh kadar air rata-rata pada lapisan tidak-jenuh (i.e. acrotelm) atau $\theta_{\mathrm{fc}}(\mathrm{mm})$, resistensi tutupan lahan terhadap kekeringan atau $R_{\mathrm{d}}(\%)$, serta kapasitas lapang pada lapisan acrotelm atau $\theta_{\mathrm{fc}}(\mathrm{mm})$. Evapotranspirasi aktual akan mengurangi kadar air pada lapisan tidak-jenuh (acrotelm) sehingga dalam algoritma neraca-air permukaan parameter tersebut tidak langsung mereduksi presipitasi bruto. Persamaan evapotranspirasi aktual yang digunakan sudah mempertimbangkan energi laten yang digunakan untuk menguapkan air pada kanopi dan efektivitas intersepsi pada transpirasi (c) sehingga terdapat pengurangan evapotranspirasi oleh intersepsi aktual.

\section{HASIL DAN PEMBAHASAN}

\subsection{Analisis Temporal}

Hasil simulasi model KATARA dapat dianalisis secara temporal maupun spasial dengan ekstensi ASCII dan CSV. Keluaran model yang berekstensi ASCII meiputi data overland flow, actual evapotranspiration, actual interception, net precipitation, precipitation gross, dan water loss. Namun, pembahasan pada makalah ini akan dibatasi pada beberapa parameter yang berhubungan erat dengan banjir dan data untuk validasi.

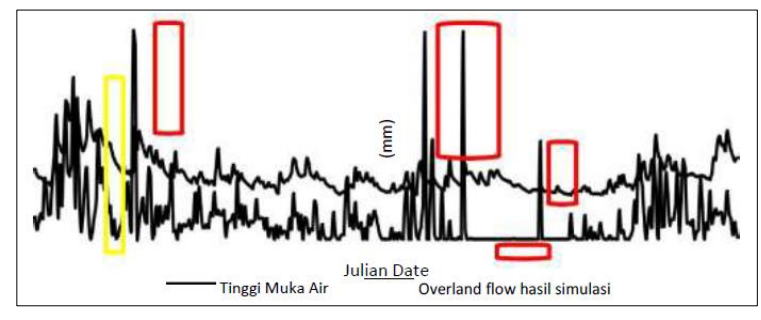

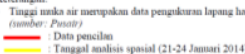

Gambar 6. Output model KATARA (temporal): overland flow DAS Ciliwung tahun 2014 dan perbandinganya dengan tinggi muka air.

Nilai overland flow pada output model merupakan rata-rata nilai setiap piksel DAS Ciliwung dengan skala harian. Overland flow merupakan air (agent) yang terakumulasi diatas permukaan setelah adanya interaksi permukaan dan atmosfer pada model KATARA. Nilai overland flow merupakan parameter pembentuk debit setelah dijumlahkan dengan base flow, sedangkan pengukuran debit di bendung Katulampa menggunakan tinggi muka air (base flow dan ridge) yang selanjutnya dikalikan dengan faktor koreksi untuk membentuk debit. Perbedaan tersebut menyebabkan nila tinggi muka air akan selalu lebih besar dibandingkan nilai overland flow hasil simulasi. Persamaan konsep antara overland flow dan tinggi air dalam penentuan debit digunakan sebagai dasar untuk membandingkanya.

Gambar 4 menunjukkan pola grafik anatara overland flow dan tinggi muka air cenderung sama, yaitu mempunyai dua puncak pada awal dan akhir tahun 2014 (Januari, Februari, November, dan Desember). Persamaan pola tersebut menunjukkan hasil keluaran model cukup akurat untuk digunakan. Beberapa data pencilan pada nilai overland flow ditunjukkan pada gambar 4. Data pencilan tersebut dipengaruhi oleh beberapa faktor, diantaraya yaitu nilai overland flow yang dibandingkan merupakan rata-rata tiap piksel, serta data curah hujan yang digunakan merupakan data satelit (penginderaan jauh).

Tabel 1. Perbandingan nila net precipitation dan overland flow pada data pencilan.

\begin{tabular}{ccccc}
\hline $\begin{array}{l}\text { Julian } \\
\text { Date }\end{array}$ & $\begin{array}{l}\text { Net Precipitation } \\
(\mathbf{m m})\end{array}$ & $\begin{array}{l}\text { CH Observasi } \\
(\mathbf{m m})\end{array}$ & $\begin{array}{l}\text { Overland } \\
\text { flow }(\mathrm{mm})\end{array}$ & Tinggi muka air (mm) \\
\hline 51 & 73 & 55 & 21 & 7 \\
52 & 64 & 47 & 19 & 11 \\
202 & 68 & 0 & 21 & 6 \\
206 & 33 & 9 & 10 & 6 \\
241 & 0 & 0 & 0 & 6 \\
242 & 0 & 0 & 0 & 6 \\
243 & 0 & 02 & 0 & 5 \\
262 & 39 & 0 & 5 & 5 \\
\hline
\end{tabular}


Pengaruh data curah hujan terhadap data pencilan dapat dilihat pada tabel 1 . Curah hujan $(\mathrm{CH})$ observasi merupakan data pengukuran di wilayah Gadog untuk mewakili DAS Ciliwung bagian hulu. Perbedaan anatara nilai net precipitation dan $\mathrm{CH}$ observasi pada Julian date pencilan mempunyai rentang antara 0-68 $\mathrm{mm}$. Perbedaan terbesar terjadi pada Julian date 52, 202, dan 262. Perbedaan nilai $\mathrm{CH}$ observasi dan net precipitation pada model disebabkan karena perbedaan metode pengukuran.

\subsection{Analisis Spasial}

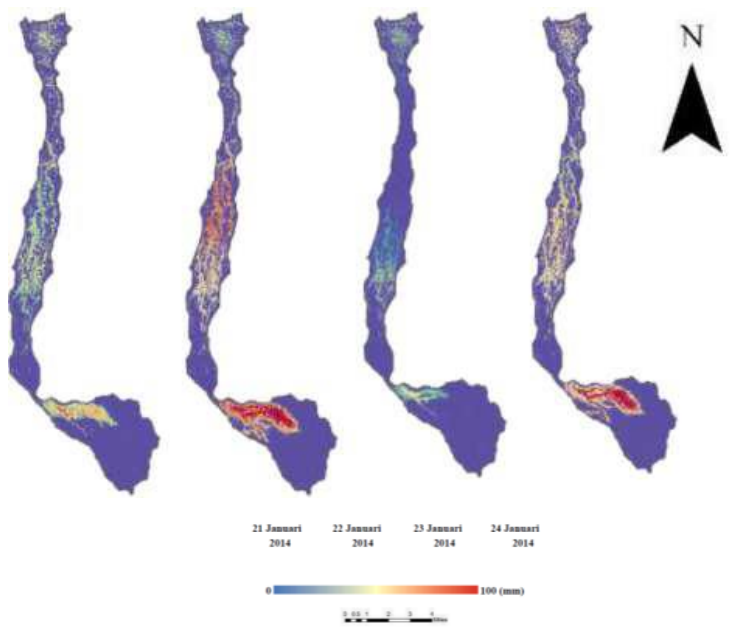

Gambar 7. Output model KATARA (spasial): overland flow tanggal 21-24 Januari 2014 di DAS Ciliwung.

Analisis kejadaian banjir pada makalah ini difokuskan pada bulan Januari 2014, hal tersebut merujuk pada data kejadian banjir 2014 dengan jumlah terbanyak pada bulan Januari (BPBD Provinsi DKI Jakarta 2014). Gambar 4 merupakan hasil simulasi model (spasial) yang terjadi di tanggal 21-24 Januari 2014. Tanggaltanggal tersebut merupakan tanggal dengan dampak banjir hampir diseluruh wilayah Jakarta (BPBD Provinsi DKI Jakarta 2014). Tanggal 21-24 Januari 2014 juga termasuk dalam satu episode banjir yang biasanya terjadi selama 1020 hari pada mode Januari-Februari (Pawitan, 2002).

Daerah Ciliwung hulu yang merupakan daerah pegunungan dengan keragaman topografi tinggi mempunyai sebaran nilai overland flow tertinggi dibandingkan dengan bagian tengah dan hilir.

Tanggal 21 dan 24 Januari mempunyai nilai overland flow tertinggi di bagian hulu, sekitar 50-100 mm. Daerah Ciliwung tengah mempunyai nilai overland flow tertinggi pada tanggal 22 Januari (40-100 $\mathrm{mm})$, disusul tanggal 24, 21, dan 23 Januari. Ciliwung tengah dengan topografi relatif landai mempunyai karakteristik overland flow yang seragam selama 21-24 Januari, nilai overland flow tertinggi terjadi pada tanggal 24 Januari (50-80 $\mathrm{mm})$.

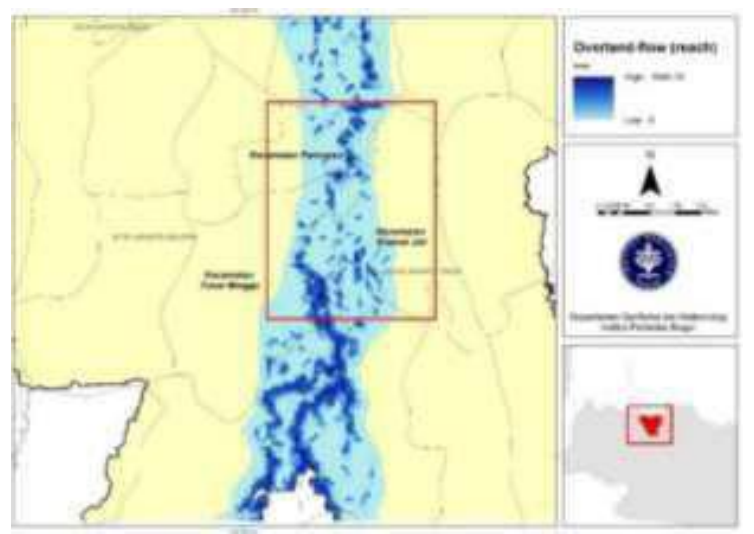

Gambar 8. Peta overland flow bulan Januari 2014 di beberapa wilayah Jakarta Selatan dan Jakarta Timur.

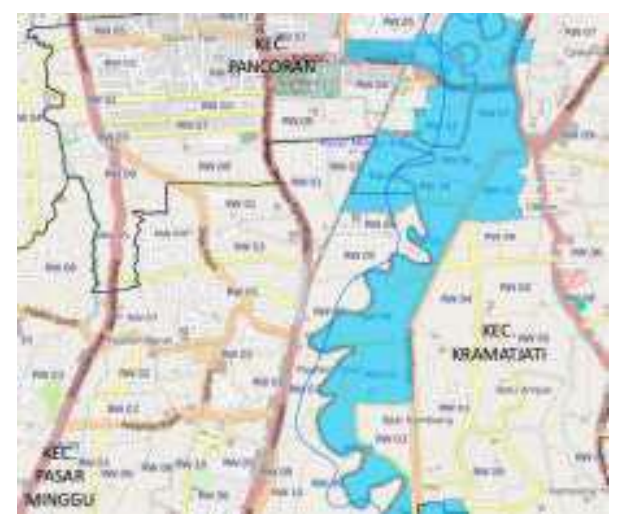

Gambar 9. Peta terdampak banjir di beberapa wilayah Jakarta Selatan dan Jakarta Timur.

Analisis spasial banjir di wilayah Jakarta difokuskan di Kecamatan Pancoran, Kramat Jati, dan Pasar Minggu. Piksel-piksel pada gambar 8 menunjukkan akumulasi overland flow selama bulan Januari 2014. Verschelling dan Udo (2007) dalam Ginting dkk., (2015), menguji pola genangan banjir di Jakarta dengan ukuran grid berbeda antara $50 \mathrm{~m}$ dengan $100 \mathrm{~m}$ dan hasilnya tidak menunjukkan perbedaan yang signifikan. Oleh karena itu, pada model KATARA digunakan ukuran piksel 100 x 100 $m$ karena dianggap dapat merepresentasikan sebaran spasial overland flow. Secara umum hasil perbandingan antara gambar 8 dan 9 cenderung mempunyai pola akumulasi genangan air yang sama. Perbedaan terdapat 
pada luas daerah genangan, hal tersebut dikarenakan perbedaan temporal data.

\section{KESIMPULAN}

Hasil simulasi model KATARA sesuai dengan tujuan utama pembangunan model, yaitu dapat menjelaskan dinamika interaksi antara atmosfer dan permukaan (process based) dan output model dapat dipahami secara spasial (spatiallyexplicit). Analisis temporal hasil simulasi model menunjukkan pola yang identik dengan data pengukuran lapang, yaitu overland flow mengalami peingkatan pada awal dan akhir tahun. Analisis spasial yang difokuskan pada beberapa tanggal banjir menunjukkan bagian hulu mempunyai nilai overland flow lebih tinggi dibandingkan bagian tengah dan hilir $(50-100 \mathrm{~mm})$. Perbandingan output spasial dengan data genangan banjir yang difokuskan pada beberapa kecamatan di Jakarta juga menunjukkan similaritas yang tinggi pada wilayah tergenang.

\section{DAFTAR PUSTAKA}

Allen R.G., Pereira L.S., Raes D., Smith M., 1998. Crop evapotranspiration guidelines for computing crop water requirements. FAO Irrigation and Drainage Paper Vol. 56 hlm 1-156.

Asdak C. 2010. Hidrologi dan Pengelolaan Daerah Aliran Sungai. Yogyakarta: Gadjah Mada University Press.

Badan Nasional Penanggulangan Bencana, 2017. Data dan Informasi Bencana Indonesia. (http://dibi.bnpb.go.id/databencana, diakses 15 Maret 2017).

Badan Penanggulangan Bencana Daerah (BPBD) Provinsi DKI Jakarta, 2014. Data Kejadian Bencana Banjir Bulan Januari 2014. (http://data.jakarta.go.id/dataset//downloa d/Data-Kejadian-Banjir-Bulan-JanuariTahun-2014.csv, diakses 15 Maret 2017)

Bartholmes J dan Todini E., 2005. Coupling meteorological and hydrological model for flood forecasting. Hydrology and erath system science vol 9 (4): 333-346.

Ginting S., Farid M., Kusuma SB., 2015. Pengembangan Peta Bahaya Banjir Berdasarkan Model Matematik Quasi 2
Dimensi. Jurnal Teknik Sipil vol 22 (3): 219-234.

Hendro, Fakhrudin, 2000. Karakteristik Curah Hujan Deras Wilayah Ciliwung Hulu. Makalah Hasil Penelitian Limnologi. Bogor: Lembaga Penelitian dan Ilmu Pengetahuan.

Holmes, R.R., 2001. Introduction to Field Methods for Hydrologic and Environmental Studies. Illinois: U.S. Geological Survey. $21 \mathrm{hlm}$.

Pawitan H, 2002. Hidrologi DAS Ciliwung dan Andilnya terhadap Banjir Jakarta. Lokakarya Pendekatan DAS dalam Menanggulangi Banjir, Jakarta.

van Noordwijk M., Farida A., Suyamto D., Lusiana B., Khasanah N., 2003. Spatial variability of rainfall governs river flow and reduces effects of land use change at landscape scale: GenRiver and SpatRain simulations. Di dalam: Post DA, editor. Modsim 2003: International Congress on Modelling and Simulation; 2003 Jul 1417; Townsville, Australia. Townsville (AU): CSIRO.hlm 572-577. 
Jurnal Meteorologi Klimatologi dan Geofisika Vol. 4 No. 3, Nopember 2017 